\title{
Níveis de Concentrado e Proteína Bruta na Dieta de Bovinos Nelore nas Fases de Recria e Terminação: Consumo e Digestibilidade ${ }^{1}$
}

\author{
Luís Carlos Vinhas Ítavo², Sebastião de Campos Valadares Filho ${ }^{3}$, Fabiano Ferreira da Silva ${ }^{4}$, \\ Rilene Ferreira Diniz Valadares ${ }^{3}$, Paulo Roberto Cecon $^{3}$, Camila Celeste Brandão Ferreira \\ Ítavo ${ }^{5}$, Eduardo Henrique Bevitori Kling de Moraes $^{5}$, Pedro Veiga Rodrigues Paulino ${ }^{5}$
}

RESUMO - Avaliaram-se os consumos e as digestibilidades aparentes dos nutrientes de dietas fornecidas para bovinos Nelore nas fases de recria e terminação. Foram utilizados 32 novilhos Nelore não-castrados, com peso médio de $240 \mathrm{~kg}$, confinados em baias individuais, na fase de recria, e 16 novilhos com peso médio de $360 \mathrm{~kg}$, na fase de terminação. Após a pesagem, os animais foram distribuídos em esquema fatorial 4 x 2 (quatro níveis de concentrado x dois níveis de proteína), com quatro repetições por tratamento na fase de recria e duas repetições na fase de terminação, em delineamento inteiramente casualizado. Os quatro níveis de concentrado utilizados nas dietas foram 20, 40, 60 e 80\% e os dois níveis de PB, 15 e 18\%, na base da MS, utilizandose o feno de capim-Tifton 85 como volumoso. Os teores máximos de NDT de 72,33\% foram estimados com 40,40\% de concentrado e não houve efeito dos teores de proteína bruta das dietas sobre as digestibilidades dos nutrientes na fase de recria. Na fase de recria, os consumos de matéria seca (MS), matéria orgânica (MO), proteína bruta (PB) e carboidratos totais (CHOT) máximos de 7,$60 ; 7,23 ; 1,30 ;$ e $5,77 \mathrm{~kg} /$ dia foram estimados para 45,$94 ; 46,94 ; 40,91$; e $48,18 \%$ de concentrado, respectivamente. O consumo da FDN apresentou redução linear com o aumento do nível de concentrado na dieta, enquanto a digestibilidade da FDN não foi alterada. Na fase de terminação, os consumos de MS, PB, FDN e FDA foram reduzidos linearmente com o aumento dos níveis de concentrado, enquanto os consumos de MO, CHOT e NDT não foram influenciados; as digestibilidades da MS e CHOT aumentaram linearmente, enquanto as da PB e EE não foram influenciadas pelos níveis de concentrados nas dietas.

Palavras-chave: níveis de concentrado, digestibilidade, níveis de proteína, consumo

\section{Concentrate and Crude Protein Levels in Growing Nelore Bulls Diets. Intake and Digestibility}

\begin{abstract}
It was aimed to evaluated the nutrients intake and digestibility of growing and finish Nellore bulls diets. It were used 32 non-castrated Nellore bulls, with $240 \mathrm{~kg}$, confined in individual stalls, in the growing phase, and 16 animals with $360 \mathrm{~kg}$ in the finishing phase. The treatments were four concentrate levels $(20,40,60$, and $80 \%)$ and two percentages of crude protein (15 and 18\%) in the diets. It was used an experimental design randomized, with four replicates, in the growing, phase and two, in the finish phase. It was used Tifton $85^{\prime}$ 'bermudagrass hay as roughage. In growing phase, the maximum dry matter (DM), organic matter (OM), crude protein (CP) and total carbohydrates (TCHO) intakes of 7.60, 7.23, 1.30, and $5.77 \mathrm{~kg} /$ day were estimated for $45.94,46.94,40.91$, and $48.18 \%$ of concentrate, respectively. The fiber intake presented linear reduction with the increase of the concentrate level in the diet, while the NDF digestibility did not differ. The TND maximum, $72.33 \%$, was estimated with $40.4 \%$ of concentrate and the crude protein content did not effect the nutrient digestibility in the growing phase. In the growing phase, maximum DM, OM, CP and TCHO intakes of 7.60, 7.23, 1.30, and $5.77 \mathrm{~kg} / \mathrm{day}$ were estimated for $45.94,46.94,40.91$, and $48.18 \%$ of concentrate, respectively. The NDF intake linear by reducted as concentrate level in the diet incresead, while the NDF digestibility did not differ. In the finishing phase, the DM, CP, NDF and ADF intakes were linearly reduced was the concentrate levels increased, while the OM, TCHO and TDN intakes were not affected. The DM and TCHO digestibility linearly increased, while the CP and EE were not affected by the concentrate levels in the diets.
\end{abstract}

Key Words: concentrate levels, digestibility, intake, protein levels

\footnotetext{
${ }_{1}^{1}$ Parte da tese de Doutorado do primeiro autor apresentada à UFV.

2 Professor da Universidade Católica Dom Bosco - UCDB, Campo Grande, MS. E.mail: itavo@ucdb.br

${ }^{3}$ Professor da UFV, Viçosa, MG. E.mail: scvfilho@ufv.br; rilene@ufv.br

${ }^{4}$ Professor da UESB, Itapetinga, BA. E.mail: ffsilva @uesb.br

5 Zootecnista, UFV. E.mail: itavo_ccbf@msn.com
} 


\section{Introdução}

O consumo pode ser limitado pelo alimento, animal ou pelas condições de alimentação (Mertens, 1994). Além disso, não se sabe como o animal ajusta o consumo e a produção a partir de seus pontos críticos ou ótimos, na tentativa de se ajustar à dieta. Se a densidade energética da ração for alta, isto é, com baixa concentração de fibra, em relação às exigências do animal, o consumo será limitado pela demanda energética do animal e o animal poderá deixar de ingerir alimentos, mesmo que o rúmen não esteja repleto. Por outro lado, se a dieta tiver baixa densidade energética, o consumo será limitado pelo enchimento. Porém, se a disponibilidade do alimento for limitada, nem o enchimento nem a demanda energética serão importantes para predizer o consumo (Mertens, 1994).

Volumosos de baixa qualidade são importantes fontes de nutrientes utilizadas na alimentação de ruminantes, principalmente nos países subdesenvolvidos. Para otimizar a utilização desses e manter a performance animal aceitável, geralmente é desejável aumentar a ingestão e digestão por meio do fornecimento de nutrientes suplementares (Köster et al., 1996). A ingestão de volumoso pode ocorrer em uma variação de 0,9 a 4,3\% do peso vivo com bovinos (Krysl et al., 1987, citados por Caton \& Dhuyvetter, 1997).

Valadares et al. (1997), estudando teores de PB na dieta de novilhos zebu, encontraram que o nível de $14,5 \%$ de $\mathrm{PB}$ proporcionou o maior consumo de MS, $\mathrm{MO}$ e NDT, quando expressos em $\mathrm{kg} / \mathrm{dia}$ e $\% \mathrm{PV}$, e obtiveram coeficientes de digestibilidade aparente da MS e MO maiores. Gesualdi Jr et al. (2000), avaliando níveis de concentrado em dietas isoprotéicas (12\% PB), em ensaio com novilhos, encontraram maiores consumos para os níveis entre 37,5 e $50,0 \%$ de concentrado na dieta.

Quando ocorre redução da porcentagem de proteína da dieta, abaixo de $12 \%$, ou diminuição da disponibilidade de compostos nitrogenados $(\mathrm{N})$, pode ocorrer queda na digestão da fibra e, subseqüentemente, restrição no consumo, em consequiência da lenta passagem dos alimentos pelo rúmen. Todavia, níveis elevados de $\mathrm{N}$ podem induzir toxidez, pelo excesso de liberação de amônia, reduzindo também o consumo. O NRC (1984) recomenda 12\% de PB para dietas de bovinos em terminação, porém
Robinson et al. (1994), citados por NRC (1996), observaram aumentos significativos no balanço de $\mathrm{N}$ de novilhos que receberam dietas balanceadas para fornecer proteína em níveis acima das exigências do NRC (1984). Ladeira et al. (1999), trabalhando com níveis crescentes de concentrado e proteína, concluíram que, ao se elevar a $\mathrm{PB}$ na ração, principalmente com fontes mais degradadas no rúmen, as perdas nitrogenadas se tornaram maiores. Cardoso et al. (2000), avaliando o efeito de níveis de concentrado sobre consumo e digestibilidade aparente total e parcial, constataram que os aumentos dos níveis não influenciaram os locais de digestão e as digestibilidades dos nutrientes apresentaram aumentos lineares em função do nível de concentrado da dieta.

Berchielli (1994), alimentando novilhos com diferentes relações de volumoso:concentrado (80:20, 60:40 e 40:60), sendo o volumoso feno de capim-coastcross, verificou maior consumo de MS para as dietas com 40 e $60 \%$ de concentrado. Já Hussein et al. (1995), estudando o efeito do nível de volumoso (70 e 30\%) na alimentação de novilhos, não observaram diferenças nos consumos de MS e MO, mas houve efeito nos consumos de FDN e FDA.

Dessa forma, foram avaliados os consumos e as digestibilidades de nutrientes em novilhos Nelore nas fases de recria e terminação, alimentados com rações contendo diferentes níveis de concentrado e proteína bruta.

\section{Material e Métodos}

O experimento foi conduzido no Laboratório de Animais e no Laboratório de Nutrição Animal do Departamento de Zootecnia da Universidade Federal de Viçosa, em Viçosa, MG.

Foram utilizados 32 novilhos Nelore não-castrados, com peso vivo médio inicial de $240 \mathrm{~kg}$, confinados em baias individuais, com piso de concreto, providas de comedouro e bebedouro de concreto, com $30 \mathrm{~m}^{2}$ de área total, sendo $8 \mathrm{~m}^{2}$ cobertos, na fase de recria, e 16 novilhos com peso médio inicial de $360 \mathrm{~kg}$ na fase de terminação.

Os animais foram pesados e distribuídos em esquema fatorial 4 x 2 (quatro níveis de concentrado $\mathrm{x}$ dois níveis de proteína), com quatro repetições por tratamento na fase de recria e duas repetições na fase de terminação, em delineamento inteiramente casualizado. Os quatro níveis de concentrado utiliza- 
dos nas dietas foram 20, 40, 60 e $80 \%$ e os dois níveis de PB, 15 e 18\%, na base da MS. Após o período de adaptação, o consumo e a digestibilidade dos nutrientes foram avaliados durante uma semana nas fases de recria e terminação. As coletas foram realizadas durante o segundo mês de confinamento, para os animais de recria (até $360 \mathrm{~kg}$ ), e durante o quinto mês de confinamento, para os animais do grupo de terminação (até $450 \mathrm{~kg}$ )

Foram realizadas duas coletas de fezes nesses períodos, em dois dias consecutivos, sendo no primeiro dia às $10 \mathrm{~h}$ e no segundo, às $16 \mathrm{~h}$, de acordo com metodologia descrita por Ítavo (2001).

O volumoso utilizado foi o feno de capim-Tifton 85 (Cynodon spp.). As rações foram formuladas de acordo com o NRC (1996), para conter aproximadamente $32 \%$ de compostos nitrogenados não-protéicos. As proporções dos ingredientes nos concentrados são apresentadas na Tabela 1; a composição bromatológica dos concentrados e do feno, na Tabela 2; e a composição bromatológica das dietas, na Tabela 3 .

Os alimentos foram fornecidos à vontade, uma vez ao dia, de forma a manter as sobras em torno de
5 a $10 \%$ do fornecido, estando a água permanentemente à disposição dos animais. A quantidade de ração oferecida foi registrada diariamente e, no período de coleta, foram coletadas amostras do feno e dos concentrados, por tratamento, e das sobras, por animal.

As amostras de fezes foram pré-secas em estufa de ventilação forçada, a $65^{\circ} \mathrm{C}$ por 96 horas, e processadas em moinho com peneira de $1 \mathrm{~mm}$. Finalmente, foi elaborada uma amostra composta por animal, com base no peso seco. As amostras compostas foram devidamente acondicionadas em recipientes de vidro e, posteriormente, submetidas às análises laboratoriais.

Para estimar a produção fecal, utilizou-se como indicador interno a fibra em detergente ácido indigestível (FDAi), sendo que as fezes foram incubadas no rúmen por 144 horas, tendo o resíduo sido assumido como indigestível.

As determinações de matéria seca (MS), matéria orgânica (MO), nitrogênio total, extrato etéreo (EE), fibra em detergente neutro (FDN) e macroelementos minerais ( $\mathrm{Ca}$ e $\mathrm{P}$ ) foram realizadas conforme técnicas descritas por Silva (1990), sendo que a proteína bruta (PB) foi obtida pelo produto $\mathrm{N}$ total x 6,25 . A

Tabela 1 - Proporção dos ingredientes nos concentrados, na base da matéria natural

Table 1 - Proportion of the ingredients in the concentrates, as fed basis

\begin{tabular}{|c|c|c|c|c|c|c|c|c|}
\hline \multirow{2}{*}{$\begin{array}{l}\text { Nível de concentrado }(\%) \\
\text { Level of concentrate } \\
\text { Teores de proteína bruta }(\%) \\
\text { Crude protein contents }\end{array}$} & \multicolumn{2}{|c|}{20} & \multicolumn{2}{|c|}{40} & \multicolumn{2}{|c|}{60} & \multicolumn{2}{|c|}{80} \\
\hline & 15 & 18 & 15 & 18 & 15 & 18 & 15 & 18 \\
\hline $\begin{array}{l}\text { Fubá de milho (\%) } \\
\text { Corn starch (\%) }\end{array}$ & 88,72 & 59,74 & 91,96 & 77,10 & 93,05 & 83,20 & 95,37 & 86,16 \\
\hline $\begin{array}{l}\text { Farelo de soja (\%) } \\
\text { Soybean meal (\%) }\end{array}$ & 4,75 & 32,44 & 4,38 & 18,35 & 4,03 & 13,50 & 1,75 & 11,01 \\
\hline $\begin{array}{l}\text { Uréia }(\%) \\
\text { Urea }(\%)\end{array}$ & 2,93 & 4,65 & 1,57 & 2,42 & 1,16 & 1,70 & 1,25 & 1,35 \\
\hline $\begin{array}{l}\text { Calcário calcítico }(\%) \\
\text { Calcite limestone }(\%)\end{array}$ & 0,045 & 0,02 & 0,54 & 0,79 & 0,88 & 0,87 & 1,04 & 1,04 \\
\hline $\begin{array}{l}\text { Fosfato bicálcico }(\%) \\
\text { Dicalcium phosphate }\end{array}$ & 2,78 & 2,41 & 1,12 & 0,94 & 0,57 & 0,45 & 0,33 & 0,20 \\
\hline $\begin{array}{l}\text { Sal comum }(\%) \\
\text { Salt }(\%)\end{array}$ & 0,695 & 0,65 & 0,38 & 0,36 & 0,28 & 0,26 & 0,23 & 0,21 \\
\hline $\begin{array}{l}\text { Sulfato de zinco }{ }^{1} \\
\text { Zinc sulfate }\end{array}$ & 67,20 & 67,20 & 33,60 & 33,60 & 22,40 & 22,40 & 16,80 & 16,80 \\
\hline $\begin{array}{l}\text { Sulfato de cobre }{ }^{1} \\
\text { Cupper sulfate }\end{array}$ & 16,00 & 16,00 & 8,00 & 8,00 & 5,32 & 5,32 & 4,00 & 4,00 \\
\hline $\begin{array}{l}\text { Sulfato de cobalto }{ }^{1} \\
\text { Cobalt sulfate }\end{array}$ & 0,21 & 0,21 & 0,10 & 0,10 & 0,07 & 0,07 & 0,05 & 0,05 \\
\hline $\begin{array}{l}\text { Iodato de potássio }{ }^{1} \\
\text { Potassium iodate }\end{array}$ & 0,42 & 0,42 & 0,21 & 0,21 & 0,14 & 0,14 & 0,105 & 0,105 \\
\hline $\begin{array}{l}\text { Selenito de sódio } \\
\text { Sodium selenite } \\
\end{array}$ & 0,21 & 0,21 & 0,105 & 0,105 & 0,07 & 0,07 & 0,05 & 0,05 \\
\hline
\end{tabular}

1 (g/100kg).

R. Bras. Zootec., v.31, n.2, p.1033-1041, 2002 (suplemento) 
Tabela 2 - Teores médios de matéria seca (MS), matéria orgânica (MO), proteína bruta (PB), extrato etéreo (EE), fibra em detergente neutro (FDN), carboidratos não-fibrosos (CNF), cálcio (Ca) e fósforo (P) dos concentrados e do feno

Table 2 - Average contents of dry matter (DM), organic matter (OM), crude protein (CP), ether extract (EE), neutral detergent fiber (NDF), non fiber carbohydrates (NFC), calcium (Ca) and phosphorus ( $P$ ) of concentrates and hay

\begin{tabular}{|c|c|c|c|c|c|c|c|c|c|}
\hline \multirow{2}{*}{$\begin{array}{l}\text { Concentrado }(\%) \\
\text { Concentrate } \\
\text { Teores de PB }(\%) \\
C P \text { contents }\end{array}$} & \multicolumn{2}{|c|}{20} & \multicolumn{2}{|c|}{40} & \multicolumn{2}{|c|}{60} & \multicolumn{2}{|c|}{80} & \multirow{2}{*}{$\begin{array}{c}\text { Feno } \\
\text { Hay }\end{array}$} \\
\hline & 15 & 18 & 15 & 18 & 15 & 18 & 15 & 18 & \\
\hline $\begin{array}{l}\mathrm{MS}, \% \\
D M\end{array}$ & 87,30 & 87,19 & 87,29 & 87,41 & 87,33 & 87,45 & 88,55 & 86,85 & 88,55 \\
\hline $\begin{array}{l}\mathrm{MO}^{1} \\
O M\end{array}$ & 95,77 & 94,08 & 96,37 & 96,00 & 97,02 & 96,43 & 96,55 & 96,79 & 94,18 \\
\hline $\begin{array}{l}\mathrm{PB}^{1} \\
C P\end{array}$ & 21,98 & 37,87 & 16,62 & 22,93 & 15,78 & 21,03 & 14,63 & 17,86 & 14,09 \\
\hline $\begin{array}{l}\mathrm{EE}^{1} \\
\mathrm{FDN}^{1,2}\end{array}$ & $\begin{array}{r}2,78 \\
14,01\end{array}$ & $\begin{array}{l}1,53 \\
5,16\end{array}$ & $\begin{array}{l}4,30 \\
9,86\end{array}$ & $\begin{array}{l}1,13 \\
4,45\end{array}$ & $\begin{array}{r}2,66 \\
13,53\end{array}$ & $\begin{array}{l}2,10 \\
8,05\end{array}$ & $\begin{array}{r}1,89 \\
13,81\end{array}$ & $\begin{array}{l}1,87 \\
5,94\end{array}$ & $\begin{array}{r}1,93 \\
74,47\end{array}$ \\
\hline $\begin{array}{l}N D F \\
\mathrm{CNF}^{1} \\
N F C\end{array}$ & 57,00 & 49,52 & 65,59 & 67,49 & 65,05 & 62,25 & 66,22 & 71,12 & 3,69 \\
\hline $\begin{array}{l}\mathrm{Ca}^{1} \\
\mathrm{P}^{1}\end{array}$ & $\begin{array}{l}0,96 \\
0,95\end{array}$ & $\begin{array}{l}1,01 \\
1,01\end{array}$ & $\begin{array}{l}0,70 \\
0,48\end{array}$ & $\begin{array}{l}0,79 \\
0,64\end{array}$ & $\begin{array}{l}0,71 \\
0,40\end{array}$ & $\begin{array}{l}0,63 \\
0,46\end{array}$ & $\begin{array}{l}0,84 \\
0,50\end{array}$ & $\begin{array}{l}0,75 \\
0,38\end{array}$ & $\begin{array}{l}0,36 \\
0,20\end{array}$ \\
\hline
\end{tabular}

$1 \%$ na matéria seca (\% in dry matter).

${ }^{2}$ FDN corrigida para cinzas e proteína (NDF corrected for ash and protein).

Tabela 3 - Teores médios de matéria seca (MS), matéria orgânica (MO), proteína bruta (PB), extrato etéreo (EE), fibra em detergente neutro (FDN), carboidratos não-fibrosos (CNF), nutrientes digestíveis totais (NDT), cálcio (Ca) e fósforo $(P)$ das dietas experimentais

Table 3 - Average contents of dry matter (DM), organic matter (OM), crude protein (CP), ether extract (EE), neutral detergent fiber (NDF), non fiber carbohydrates (NFC), total digestible nutrients (TDN), calcium (Ca) and phosphorus ( $P$ ) of experimental diets

\begin{tabular}{|c|c|c|c|c|c|c|c|c|}
\hline \multirow{2}{*}{$\begin{array}{l}\text { Nível de concentrado (\%) } \\
\text { Level of concentrate } \\
\text { Teores de proteína bruta }(\%) \\
\text { Crude protein contents }\end{array}$} & \multicolumn{2}{|c|}{20} & \multicolumn{2}{|c|}{40} & \multicolumn{2}{|c|}{60} & \multicolumn{2}{|c|}{80} \\
\hline & 15 & 18 & 15 & 18 & 15 & 18 & 15 & 18 \\
\hline $\begin{array}{l}\mathrm{MS}, \% \\
D M\end{array}$ & 88,21 & 88,28 & 88,05 & 88,09 & 87,79 & 87,92 & 87,58 & 87,67 \\
\hline $\begin{array}{l}\mathrm{MO}^{1} \\
O M\end{array}$ & 94,50 & 94,16 & 95,06 & 94,91 & 95,88 & 95,53 & 96,08 & 96,27 \\
\hline $\begin{array}{l}\mathrm{PB}^{1} \\
C P\end{array}$ & 15,67 & 18,85 & 15,10 & 17,63 & 15,11 & 18,26 & 14,52 & 17,11 \\
\hline $\begin{array}{l}\mathrm{EE}^{1} \\
\mathrm{FDN}^{1,2}\end{array}$ & $\begin{array}{r}2,30 \\
62,37\end{array}$ & $\begin{array}{r}2,05 \\
60,60\end{array}$ & $\begin{array}{r}3,03 \\
48,62\end{array}$ & $\begin{array}{r}1,76 \\
46,46\end{array}$ & $\begin{array}{r}2,46 \\
37,90\end{array}$ & $\begin{array}{r}2,13 \\
34,62\end{array}$ & $\begin{array}{r}1,95 \\
25,94\end{array}$ & $\begin{array}{r}1,93 \\
19,65\end{array}$ \\
\hline $\begin{array}{l}N D F \\
\mathrm{CNF}^{1} \\
N F C\end{array}$ & 14,16 & 12,66 & 28,31 & 29,06 & 40,41 & 40,52 & 53,67 & 57,58 \\
\hline $\begin{array}{l}\mathrm{Ca}^{1} \\
\mathrm{P}^{1}\end{array}$ & $\begin{array}{l}0,48 \\
0,35\end{array}$ & $\begin{array}{l}0,49 \\
0,37\end{array}$ & $\begin{array}{l}0,50 \\
0,31\end{array}$ & $\begin{array}{l}0,53 \\
0,39\end{array}$ & $\begin{array}{l}0,57 \\
0,32\end{array}$ & $\begin{array}{l}0,52 \\
0,36\end{array}$ & $\begin{array}{l}0,74 \\
0,44\end{array}$ & $\begin{array}{l}0,67 \\
0,34\end{array}$ \\
\hline
\end{tabular}

$1 \%$ na matéria seca (\% in dry matter).

2 FDN corrigida para cinzas e proteína (NDF corrected for ash and protein).

solução mineral para determinação dos macroelementos minerais foi preparada por via úmida. Após as devidas diluições, o teor de fósforo foi determinado por colorimetria e o de cálcio, em espectrofotômetro de absorção atômica.

\section{R. Bras. Zootec., v.31, n.2, p.1033-1041, 2002 (suplemento)}

Os carboidratos totais (CHOT) foram obtidos por intermédio da equação: $100-(\% \mathrm{~PB}+\% \mathrm{EE}+$ \%Cinzas) (Sniffen et al., 1992), enquanto os carboidratos não-fibrosos (CNF), pela diferença entre $\mathrm{CHOT}$ e FDN. Os teores de nutrientes digestíveis 
totais (NDT) foram obtidos conforme recomendações de Sniffen et al. (1992).

Os dados foram analisados por meio de análise de variância e regressão. Os modelos foram escolhidos com base na significância dos coeficientes de regressão utilizando-se o teste $\mathrm{F}$, adotando $10 \%$ de probabilidade, no coeficiente de determinação e no parâmetro estudado. Para comparar as médias das variáveis, para verificar o efeito do teor de PB, utilizou-se o teste F, em nível de 5\% utilizando-se o Sistema de Análises Estatísticas e Genéticas - SAEG (UFV/CPD, 1997).

\section{Resultados e Discussão}

Não houve interação $(\mathrm{P}>0,05)$ entre os níveis de concentrado e os teores de proteína bruta das dietas para os consumos de matéria seca, matéria orgânica, proteína bruta, carboidratos totais, fibra em detergente neutro e fibra em detergente ácido.
As médias e equações de regressão ajustadas para o consumo de nutrientes, em kg/dia, em bovinos Nelore na fase de recria, em função do nível de concentrado e de proteína bruta nas dietas, estão apresentadas na Tabela 4.

Os consumos de MS, MO, PB e CHOT apresentaram comportamento quadrático, observando-se valores máximos de 7,60; 7,23; 1,30; e 5,77 kg/dia com 45,94; 46,94; 40,91; e 48,18\% de concentrado, respectivamente. Os consumos de fibras em detergente neutro (CFDN) e em detergente ácido (CFDA) apresentaram redução linear com o aumento do nível de concentrado na dieta. Tal fato era esperado, uma vez que a porcentagem de FDN reduziu com o aumento da quantidade de concentrado.

Não houve efeito dos teores de PB sobre os consumos dos nutrientes, com exceção do consumo de PB, que foi maior para as dietas contendo $18 \%$ de PB. Tais resultados estão de acordo com os apresentados por Valadares et al. (1997), em que o nível de

Tabela 4 - Médias, coeficientes de variação $(C V)$ e de determinação e equações de regressão ajustadas para o consumo de nutrientes ( $\mathrm{kg} / \mathrm{dia})$, em bovinos Nelore na fase de recria, em função do nível (n) de concentrado e dos teores de proteína bruta (PB) nas dietas

Table 4 - Means, coefficients of variation (CV) and determination and fitted regression equations for the nutrients intake ( $\mathrm{kg} / \mathrm{day}$ ), on the level of concentrate $(n)$ and crude protein $(C P)$ contents of the diets fed to Nellore bulls in the growing phase

\begin{tabular}{|c|c|c|c|c|c|c|c|}
\hline \multirow[t]{2}{*}{$\begin{array}{l}\text { Variáveis } \\
\text { Variables }\end{array}$} & \multicolumn{4}{|c|}{$\begin{array}{l}\text { Nível de concentrado (\%) } \\
\text { Level of concentrate (\%) }\end{array}$} & \multicolumn{2}{|c|}{$\begin{array}{c}\text { Teores de } \mathrm{PB}(\%) \\
C P \text { contents }(\%)\end{array}$} & \multirow[t]{2}{*}{$\begin{array}{l}\mathrm{CV} \\
(\%)\end{array}$} \\
\hline & 20 & 40 & 60 & 80 & 15 & 18 & \\
\hline $\mathrm{CMS}^{1}$ & 6,89 & 7,45 & 7,48 & 6,29 & $6,65^{\mathrm{a}}$ & $7,41^{\mathrm{a}}$ & 20,04 \\
\hline $\mathrm{CMS}^{2}(\% \mathrm{PV})$ & 2,87 & 3,11 & 3,12 & 2,62 & $2,77^{\mathrm{a}}$ & $3,09^{\mathrm{a}}$ & 20,04 \\
\hline $\mathrm{CMS}^{3}\left(\mathrm{~g} / \mathrm{kgPV}^{0,75}\right)$ & 113,31 & 122,63 & 123,04 & 103,39 & $109,36^{\mathrm{a}}$ & $121,82^{\mathrm{a}}$ & 20,04 \\
\hline $\mathrm{CMO}^{4}$ & 6,50 & 7,08 & 7,16 & 6,05 & $6,35^{a}$ & $7,04^{\mathrm{a}}$ & 20,05 \\
\hline $\mathrm{CPB}^{5}$ & 1,24 & 1,24 & 1,28 & 1,01 & $1,02^{\mathrm{b}}$ & $1,36^{\mathrm{a}}$ & 19,37 \\
\hline $\mathrm{CCHOT}^{6}$ & 5,13 & 5,67 & 5,70 & 4,91 & $5,17^{\mathrm{a}}$ & $5,54^{\mathrm{a}}$ & 20,22 \\
\hline $\mathrm{CFDN}^{7}$ & 4,38 & 3,76 & 2,80 & 1,58 & $3,00^{\mathrm{a}}$ & $3,26^{\mathrm{a}}$ & 20,17 \\
\hline $\mathrm{CFDN}^{8}(\% \mathrm{PV})$ & 1,83 & 1,57 & 1,17 & 0,66 & $1,25^{\mathrm{a}}$ & $1,36^{\mathrm{a}}$ & 20,17 \\
\hline $\mathrm{CFDN}^{9}\left(\mathrm{~g} / \mathrm{kgPV}^{0,75}\right)$ & 71,86 & 61,71 & 45,92 & 25,99 & $49,24^{\mathrm{a}}$ & $53,50^{\mathrm{a}}$ & 20,17 \\
\hline $\mathrm{CFDA}^{10}$ & 2,06 & 1,72 & 1,20 & 0,60 & $1,32^{\mathrm{a}}$ & $1,47^{\mathrm{a}}$ & 20,60 \\
\hline
\end{tabular}

CMS = consumo de matéria seca; $\mathrm{CMO}=$ consumo de matéria orgânica; $\mathrm{CPB}=$ consumo de proteína bruta; $\mathrm{CCHOT}=$ consumo de carboidratos totais; CFDN = consumo de fibra em detergente neutro; CFDA = consumo de fibra em detergente ácido.

\# Médias seguidas de mesma letra na linha não diferem pelo teste $F(P>0,05)$.

${ }^{* * *}$ Significância das equações de regressão $(P<0,10)$.

$D M I=$ dry matter intake; $\mathrm{OMI}=$ organic matter intake; $\mathrm{CPI}=$ crude protein intake; $E \mathrm{EI}=$ ether extract intake; $\mathrm{TCHOI}=$ total carbohydrates intake; $N D F I=$ neutral detergent fiber intake; $A D F I=$ acid detergent fiber intake.

\# Means within a column followed by the same letters do not differ $(P>$.05) by $F$ test.

*** Significance of the regression equations $(P<.10)$.

$Y=5,27258+0,101120^{* * *} n-0,00110038^{* * *} n^{2}\left(R^{2}=0,98\right)$.

$2 \mathrm{Y}=2,19691+0,0421335^{\star \star *} \mathrm{n}-0,000458493^{\star \star *} \mathrm{n}^{2}\left(\mathrm{R}^{2}=0,98\right)$.

$3 \mathrm{Y}=86,7258+1,66327^{* * *} n-0,0180996^{* * *} n^{2}\left(R^{2}=0,98\right)$.

$4 Y=4,90674+0,099158^{* * *} n-0,00105618^{* * *} n^{2}\left(R^{2}=0,97\right)$.

$5 \mathrm{Y}=1,00501+0,0142165^{* * *} \mathrm{n}-0,000173737^{* * *} n^{2}\left(\mathrm{R}^{2}=0,87\right)$.

$6 Y=3,83771+0,0803415^{\star \star *} n-0,000833745^{\star \star *} n^{2}\left(R^{2}=0,99\right)$.

$7 \quad \mathrm{Y}=5,47097-0,0467733^{\star \star *} n\left(r^{2}=0,98\right)$.

$8 Y=2,27957-0,0194889^{* * *} n\left(r^{2}=0,98\right)$.

$9 \mathrm{Y}=89,7234-0,767077^{\star * *} \mathrm{n}\left(\mathrm{r}^{2}=0,98\right)$.

$10 Y=2,61840-0,0244815^{\star * *} n\left(r^{2}=0,99\right)$.

\section{R. Bras. Zootec., v.31, n.2, p.1033-1041, 2002 (suplemento)}


14,5\% PB na dieta foi o que proporcionou maior consumo de MS. Em média, o consumo de MS, expresso em \% PV, foi 2,77 e 3,09\% PV para as dietas com 15 e $18 \%$ PB, respectivamente. Estes valores foram superiores aos apresentados por Valadares et al. (1997), Ferreira et al. (1999), Ladeira et al. (1999) e Gesualdi Jr et al. (2000).

As médias para o consumo de EE estão apresentadas na Tabela 5. Houve interação entre o nível de concentrado e a porcentagem de proteína da dieta. Para os níveis de concentrado que continham $15 \%$ de $\mathrm{PB}$, o consumo de EE apresentou comportamento quadrático, estimando-se valor máximo de $0,209 \mathrm{~kg}$ com $46,41 \%$ de concentrado. Todavia, o tratamento com $18 \%$ de proteína apresentou menor consumo de $\mathrm{EE}(\mathrm{P}<0,05)$, com $40 \%$ de concentrado.

As médias e equações de regressão ajustadas para os coeficientes de digestibilidade aparente dos nutrientes e NDT, em função do nível de concentrado e dos teores de PB nas dietas de bovinos Nelore na fase de recria, estão apresentadas na Tabela 6. O nível de concentrado não influenciou a digestibilidade da FDN, cujo valor médio foi de $74,17 \%$. Tal fato sugere que não houve efeito associativo ou qualquer influência das quantidades de amido da dieta sobre a digestão da fibra.

Os coeficientes de digestibilidade aparente de MS, FDA e CHOT apresentaram comportamento quadrático, estimando-se valores máximos para MS

Tabela 5 - Médias e equação de regressão ajustada para o consumo de extrato etéreo $(E E)$ em bovinos Nelore na fase de recria, por porcentagem de proteína bruta da dieta e em função do nível ( $n$ ) de concentrado na dieta e seu respectivo coeficiente de determinação

Table 5 - Means and fitted regression equations for the ether extract (EE) intake, on the level of concentrate (n) and crude protein $(\mathrm{CP})$ percentage of the diets fed to Nellore bulls in the growing phase, and the respective coefficient of determination

Teor de PB (\%) Nível de concentrado (\%) CV

CP content (\%) Level of concentrate (\%)

\begin{tabular}{cccccc} 
& 20 & 40 & 60 & 80 & \\
\hline $15^{1}$ & $0,14^{\mathrm{A}}$ & $0,22^{\mathrm{A}}$ & $0,18^{\mathrm{A}}$ & $0,11^{\mathrm{A}}$ & 25,59 \\
$18^{2}$ & $0,13^{\mathrm{A}}$ & $0,12^{\mathrm{B}}$ & $0,15^{\mathrm{A}}$ & $0,13^{\mathrm{A}}$ & 14,87 \\
\hline
\end{tabular}

${ }^{1} Y=0,0030364+0,00889730^{* * *} n-0,0000958557^{* * *} n^{2}$ $\left(R^{2}=0,96\right)$.

$2 \mathrm{Y}=0,13$

Médias seguidas por letras iguais na coluna não diferem pelo teste $F(P>0,05)$.

Means within a column followed by the same letters do not differ $(P>.05)$ by $F$ test.

\section{R. Bras. Zootec., v.31, n.2, p.1033-1041, 2002 (suplemento)}

e FDA de 78,85 e 77,55\% com 59,68 e 52,15\% de concentrado, respectivamente. Estimaram-se digestibilidade mínima de CHOT de 72,39\% com $41,95 \%$ de concentrado, respectivamente (Tabela 6). O NDT calculado também apresentou comportamento quadrático, observando-se valor mínimo de $72,33 \%$ com $40,40 \%$ de concentrado.

Não houve efeito dos teores de PB sobre os coeficientes de digestibilidade aparente dos nutrientes e teores de NDT $(P>0,05)$. Os resultados para o tratamento com 15\% PB foram similares aos de Ladeira et al. (1999) e superiores aos de Dias et al. (2000) e Valadares et al. (1997), que utilizaram $14,5 \%$ de PB na dieta e $45 \%$ de concentrado.

As médias e equações de regressão ajustadas para os consumos de nutrientes, em kg/dia, em bovinos Nelore na fase de terminação, em função do nível de concentrado e dos teores de proteína bruta nas dietas, estão apresentadas na Tabela 7. Os consumos de MS, PB, FDN e FDA apresentaram redução linear com o aumento do nível de concentrado na dieta, enquanto o consumo de EE máximo de $0,179 \mathrm{~kg}$ foi estimado com $39,6 \%$ de concentrado da dieta. Já os consumos de MO, CHOT e NDT não foram alterados pelo nível de concentrado na dieta, apresentando médias de 7,26; 5,85; e 6,0 kg/dia, respectivamente. Somente os consumos de PB, FDN e FDA foram afetados pelos teores de proteína bruta das dietas, sendo maiores $(\mathrm{P}<0,05)$ para a dieta com $18 \%$ de $\mathrm{PB}$.

As médias de consumo de MS em porcentagem do peso vivo (\%PV) para as dietas com 15 e $18 \%$ de PB foram 1,94 e 2,20\% (Tabela 7). Tais valores foram inferiores às porcentagens apresentadas pelos animais na fase de recria, na qual se consumos de MS, para os animais que estavam recebendo as dietas com 15 e $18 \%$ de PB, de 2,77 e 3,09\% do PV. Também houve diferença entre os valores de consumo de FDN em porcentagem do PV entre os animais nas fases de recria e terminação. Os animais durante a fase de recria consumiram 1,25 e 1,36\% do PV, respectivamentes para as dietas com 15 e $18 \%$ de $\mathrm{PB}$, enquanto os animais na fase de terminação obtiveram consumos de 0,86 e $0,99 \%$ do PV. Tais fatos sugerem que os animais durante a fase de crescimento apresentam maior potencial de consumo de nutrientes.

Há de se destacar que, numericamente, as médias de consumo dos nutrientes e NDT, para o tratamento com 18\% de PB, foram maiores. Valadares et al. (1997) observaram relação linear $(\mathrm{P}<0,001)$ entre 
Tabela 6 - Médias, coeficientes de variação (CV) e de determinação $\left(R^{2}\right)$ e equações de regressão ajustadas para as digestibilidades aparentes de matéria seca (MS), matéria orgânica (MO), proteína bruta (PB), extrato etéreo $(E E)$, carboidratos totais (CHOT), fibras em detergente neutro (FDN) e detergente ácido (FDA) e nutrientes digestíveis totais (NDT), em função do nível (n) de concentrado e dos teores de PB das dietas de bovinos Nelore, na fase de recria

Table 6 - Means, coefficients of variation $(C V)$ and determination $\left(R^{2}\right)$ and fitted regression equations for the dry matter (DM), organic matter (OM), crude protein (CP), ether extract (EE), total carbohydrates (TCHO), neutral detergent fiber (NDF) and acid detergent fiber (ADF) apparent digestibilities and total digestible nutrients (TDN) on the level of concentrate (n) and crude protein $(C P)$ contents of the diets fed to Nellore bulls in the growing phase

\begin{tabular}{|c|c|c|c|c|c|c|c|}
\hline \multirow[t]{2}{*}{$\begin{array}{l}\text { Variáveis } \\
\text { Variables }\end{array}$} & \multicolumn{4}{|c|}{$\begin{array}{c}\text { Nível de concentrado }(\%) \\
\text { Level of concentrate }(\%)\end{array}$} & \multicolumn{2}{|c|}{$\begin{array}{c}\text { Teores de } \mathrm{PB}(\%) \\
C P \text { contents }(\%) \\
\end{array}$} & \multirow[t]{2}{*}{$\begin{array}{l}\mathrm{CV} \\
(\%)\end{array}$} \\
\hline & 20 & 40 & 60 & 80 & 15 & 18 & \\
\hline $\mathrm{MS}^{1}$ & 72,37 & 76,21 & 79,82 & 76,74 & $76,03^{a}$ & $76,54^{\mathrm{a}}$ & 5,42 \\
\hline $\mathrm{MO}^{2}$ & 77,01 & 76,49 & 80,09 & 80,49 & $79,54^{\mathrm{a}}$ & $77,50^{\mathrm{a}}$ & 3,97 \\
\hline $\mathrm{PB}^{3}$ & 79,26 & 81,17 & 82,16 & 84,11 & $80,22^{\mathrm{a}}$ & $83,14^{\mathrm{a}}$ & 4,94 \\
\hline $\mathrm{EE}^{4}$ & 77,14 & 80,11 & 84,24 & 87,36 & $81,54^{\mathrm{a}}$ & $82,88^{a}$ & 13,10 \\
\hline $\mathrm{CHOT}^{5}$ & 75,46 & 70,78 & 75,72 & 79,43 & $75,81^{\mathrm{a}}$ & $74,88^{a}$ & 5,14 \\
\hline $\mathrm{FDN}^{6}$ & 73,87 & 73,58 & 75,75 & 73,50 & $74,74^{\mathrm{a}}$ & $73,60^{\mathrm{a}}$ & 6,06 \\
\hline $\mathrm{FDA}^{7}$ & 73,30 & 75,46 & 78,68 & 73,54 & $74,96^{\mathrm{a}}$ & $75,53^{\mathrm{a}}$ & 4,35 \\
\hline $\mathrm{NDT}^{8}$ & 74,81 & 70,93 & 75,59 & 79,44 & $75,46^{\mathrm{a}}$ & $74,92^{\mathrm{a}}$ & 5,05 \\
\hline
\end{tabular}

${ }^{* * *}$ Significância das equações de regressão $(P<0,10)\left(^{* * *}\right.$ Significance of the regression equations $\left.[P<.10]\right)$.

${ }^{1} Y=63,4546+0,515889^{\star \star \star} n-0,00432187^{\star \star \star} n^{2}\left(R^{2}=0,93\right) ;{ }^{2} Y=78,52$

${ }^{3} \mathrm{Y}=77,7888+0,0777824^{* * *} \mathrm{n}\left(\mathrm{r}^{2}=0,99\right)$.

${ }^{4} Y=73,5151+0,173905^{* * *} n\left(r^{2}=0,99\right)$.

${ }^{5} Y=81,6111-0,439756^{* * *} n+0,00524170^{* * *} n^{2}\left(R^{2}=0,84\right) ;{ }^{6} Y=74,17$

${ }^{7} Y=65,1427+0,475626^{* * *} n-0,00455998^{* * *} n^{2}\left(R^{2}=0,76\right)$.

${ }^{8} Y=80,2218-0,390771^{* * *} n+0,00483570^{\star * *} n^{2}\left(R^{2}=0,88\right)$.

Tabela 7 - Médias, coeficientes de variação $(C V)$ e de determinação $\left(R^{2}\right)$ e equações de regressão ajustadas para o consumo de nutrientes (kg/dia) em bovinos Nelore na fase de terminação, em função do nível (n) de concentrado e dos teores de proteína bruta (PB) nas dietas

Table 7 - Means, coefficients of variation $(\mathrm{CV})$ and determination $\left(R^{2}\right)$ and fitted regression equations for the nutrients intake $(\mathrm{kg} /$ day), on the level of concentrate (n) and crude protein (CP) contents of the diets fed to Nellore bulls in the finishing phase

\begin{tabular}{|c|c|c|c|c|c|c|c|}
\hline \multirow[t]{2}{*}{$\begin{array}{l}\text { Variáveis } \\
\text { Variables }\end{array}$} & \multicolumn{4}{|c|}{$\begin{array}{l}\text { Nível de concentrado }(\%) \\
\text { Level of concentrate }(\%)\end{array}$} & \multicolumn{2}{|c|}{$\begin{array}{c}\text { Teores de } \mathrm{PB}(\%) \\
\text { CP contents }(\%)\end{array}$} & \multirow[t]{2}{*}{$\begin{array}{l}\mathrm{CV} \\
(\%)\end{array}$} \\
\hline & 20 & 40 & 60 & 80 & 15 & 18 & \\
\hline $\mathrm{CMS}^{1}$ & 7,97 & 7,97 & 6,93 & 6,95 & $7,00^{\mathrm{a}}$ & $7,91^{\mathrm{a}}$ & 12,77 \\
\hline $\mathrm{CMS}^{2}(\% \mathrm{PV})$ & 2,21 & 2,21 & 1,92 & 1,93 & $1,94^{\mathrm{a}}$ & $2,20^{\mathrm{a}}$ & 12,77 \\
\hline $\mathrm{CMS}^{3}\left(\mathrm{~g} / \mathrm{kgPV}^{0,75}\right)$ & 96,40 & 96,40 & 83,81 & 84,15 & 84,69 & 95,69 & 12,77 \\
\hline $\mathrm{CMO}^{4}$ & 7,66 & 7,75 & 6,74 & 6,87 & $6,84^{\mathrm{a}}$ & $7,68^{\mathrm{a}}$ & 12,87 \\
\hline $\mathrm{CPB}^{5}$ & 1,41 & 1,33 & 1,17 & 1,10 & $1,07^{\mathrm{b}}$ & $1,43^{\mathrm{a}}$ & 12,41 \\
\hline $\mathrm{CEE}^{6}$ & 0,16 & 0,18 & 0,15 & 0,13 & $0,16^{\mathrm{a}}$ & $0,15^{\mathrm{a}}$ & 12,81 \\
\hline $\mathrm{CCHOT}^{7}$ & 6,09 & 6,25 & 5,42 & 5,64 & $5,60^{\mathrm{a}}$ & $6,10^{\mathrm{a}}$ & 13,01 \\
\hline $\mathrm{CFDN}^{8}$ & 5,02 & 3,94 & 2,62 & 1,73 & $3,11^{\mathrm{b}}$ & $3,55^{\mathrm{a}}$ & 11,29 \\
\hline $\mathrm{CFDN}^{9}(\% \mathrm{PV})$ & 1,39 & 1,09 & 0,73 & 0,48 & $0,86^{b}$ & $0,99^{a}$ & 11,29 \\
\hline $\mathrm{CFDN}^{10}\left(\mathrm{~g} / \mathrm{kgPV}^{0,75}\right)$ & 60,77 & 47,67 & 31,69 & 20,95 & $37,59^{\mathrm{a}}$ & $42,95^{\mathrm{a}}$ & 11,29 \\
\hline $\mathrm{CFDA}^{11}$ & 2,35 & 1,79 & 1,13 & 0,66 & $1,37^{b}$ & $1,60^{\mathrm{a}}$ & 11,12 \\
\hline $\mathrm{CNDT}^{12}$ & 6,06 & 6,49 & 5,66 & 5,80 & $5,62^{\mathrm{a}}$ & $6,39^{\mathrm{a}}$ & 12,66 \\
\hline
\end{tabular}

CMS = consumo de matéria seca; $\mathrm{CMO}=$ consumo de matéria orgânica; $\mathrm{CPB}=$ consumo de proteína bruta; $\mathrm{CEE}=$ consumo de extrato etéreo; $\mathrm{CCHOT}$ = consumo de carboidratos totais; CFDN = consumo de fibra em detergente neutro; CFDA = consumo de fibra em

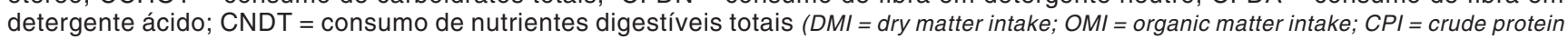
intake; $E E I=$ ether extract intake; $T C H O I=$ total carbohydrates intake; NDFI = neutral detergent fiber intake; $A D F I=$ acid detergent fiber intake; $T D N I=$ total digestible nutrients intake).

$1 \quad \mathrm{Y}=8,47367-0,0203958^{* * *} \mathrm{n}\left(\mathrm{r}^{2}=0,79\right)$.

$2 Y=2,3538-0,00566549^{* \star *} n\left(r^{2}=0,79\right)$.

$\mathrm{Y}=102,5290-0,246782^{\star * *} \mathrm{n}\left(\mathrm{r}^{2}=0,79\right)$.

$\mathrm{Y}=7,26 ; 5 \mathrm{Y}=1,51932-0,00534406^{* \star *} \mathrm{n}\left(\mathrm{r}^{2}=0,97\right)$.

$Y=0,131926+0,00192407^{* * *} n-0,0000242938^{* * *} n^{2}\left(R^{2}=0,91\right)$.

$Y=5,85 ;{ }^{8} Y=6,12628-0,0559641^{* * *} n\left(r^{2}=0,99\right)$.

$\mathrm{Y}=1,70174-0,0155456^{\star \star *} n\left(r^{2}=0,99\right)$.

$10 \mathrm{Y}=74,1259-0,677146^{* \star *} \mathrm{n}\left(\mathrm{r}^{2}=0,99\right)$

$11 Y=2,61840-0,0244815^{* * *} n\left(r^{2}=0,99\right) ; 12 Y=6,00$. *** Significância das equações de regressão $(P<0,10)\left(^{* * *}\right.$ Significance of the regression equations $\left.[P<.10]\right)$.

\# Médias seguidas por letras iguais na linha não diferem pelo teste $F(P>0,05)$ (Means within a column followed by the same letters do not differ [P>.05]).

R. Bras. Zootec., v.31, n.2, p.1033-1041, 2002 (suplemento) 
nível de proteína da dieta e consumo de NDT, sendo o maior consumo $(3,77 \mathrm{~kg} /$ dia $)$ obtido para o nível de $14,5 \%$ de PB. Os valores de consumo de NDT foram, em média $6,0 \mathrm{~kg} / \mathrm{dia}$, não apresentando influência do nível de concentrado. Esse valor foi superior aos apresentados por Valadares et al. (1997), Ferreira et al. (1999), Ladeira et al. (1999) e Gesualdi Jr et al. (2000). Todavia, todos esses autores utilizaram dietas com porcentagens menores que $15 \%$ de $\mathrm{PB}$.

As médias e equações de regressão ajustadas para digestibilidade da MS, MO, PB, EE e CHOT, em função do nível de concentrado e dos teores de proteína bruta nas dietas de bovinos Nelore na fase de terminação, estão apresentadas na Tabela 8. Observa-se que as digestibilidades da MS e CHOT aumentaram linearmente com o aumento nos níveis de concentrado. A digestibilidade máxima da $\mathrm{MO}$ de $82,26 \%$ foi estimada com $68,3 \%$ de concentrado.

As digestibilidades da PB e EE não sofreram influência do nível de concentrado da dieta, observando-se médias de 78,17 e $83,47 \%$, respectivamente, contrariamente aos resultados observados por Cardoso et al. (2000) e Dias et al. (2000), os quais verificaram que as digestibilidades aparentes dos nutrientes apresentaram comportamento linear positivo, em função do nível de concentrado. Não houve efeito $(\mathrm{P}>0,05)$ dos teores de PB nas dietas sobre as digestibilidades aparentes dos nutrientes.

As médias e as equações de regressão ajustadas para as digestibilidades aparentes da FDN, FDA e NDT estão apresentadas na Tabela 9. Houve
Tabela 9 - Médias e equações de regressão ajustadas para digestibilidade aparente das fibras em detergente neutro (DFDN), detergente ácido (DFDA) e teores de nutrientes digestíveis totais (NDT) de bovinos Nelore na fase de terminação, em função do nível $(n)$ de concentrado e dos teores de proteína bruta (PB) das dietas e seus respectivos coeficientes de determinação

Table 9 - Means and fitted regression equations for the neutral detergent fiber (NDFD) and acid detergent fiber (ADFD) apparent digestibility and total digestible nutrients contents, on the level of concentrate $(n)$ and crude protein $(C P)$ contents of the diets and the respective coefficients of determination

\begin{tabular}{|c|c|c|c|c|c|}
\hline \multirow[t]{2}{*}{$\begin{array}{l}\mathrm{PB}(\%) \\
C P(\%)\end{array}$} & \multicolumn{4}{|c|}{$\begin{array}{c}\text { Nível de concentrado }(\%)^{\#} \\
\text { Level of concentrate }(\%)\end{array}$} & \multirow[t]{2}{*}{$\mathrm{CV}$} \\
\hline & 20 & 40 & 60 & 80 & \\
\hline \multicolumn{6}{|l|}{ DFDN } \\
\hline $\begin{array}{l}\text { NDFD } \\
15^{1}\end{array}$ & $76,86^{\mathrm{A}}$ & $77,56^{\mathrm{A}}$ & $73,90^{\mathrm{A}}$ & $78,29^{\mathrm{A}}$ & 6,22 \\
\hline $18^{2}$ & $79,13^{\mathrm{A}}$ & $76,76^{\mathrm{A}}$ & $70,39^{\mathrm{A}}$ & $61,54^{\mathrm{B}}$ & 3,88 \\
\hline \multicolumn{6}{|l|}{ DFDA } \\
\hline $15^{3}$ & $77,96^{\mathrm{A}}$ & $78,16^{\mathrm{A}}$ & $72,09^{\mathrm{A}}$ & $88,98^{\mathrm{A}}$ & 9,23 \\
\hline $18^{4}$ & $79,07^{\mathrm{A}}$ & $74,94^{\mathrm{A}}$ & $67,40^{\mathrm{A}}$ & $56,81^{\mathrm{B}}$ & 5,62 \\
\hline \multicolumn{6}{|l|}{ NDT } \\
\hline$T D N$ & & & & & \\
\hline $15^{5}$ & $75,73^{\mathrm{A}}$ & $79,90^{\mathrm{A}}$ & $80,21^{\mathrm{B}}$ & $85,36^{\mathrm{A}}$ & 2,01 \\
\hline $18^{6}$ & $76,35^{\mathrm{A}}$ & $83,05^{\mathrm{A}}$ & $83,04^{\mathrm{A}}$ & $81,36^{\mathrm{A}}$ & 1,61 \\
\hline
\end{tabular}

${ }^{1} \mathrm{Y}=76,65 ; \quad{ }^{2} \mathrm{Y}=86,7345-0,295581^{* \star *} \mathrm{n}\left(\mathrm{r}^{2}=0,94\right)$.

${ }^{3} \mathrm{Y}=79,29 ; \quad{ }^{4} \mathrm{Y}=88,1370-0,371587^{* * *} \mathrm{n}\left(\mathrm{r}^{2}=0,96\right)$

${ }^{5} Y=72,9957+0,146123^{* * *} n\left(r^{2}=0,91\right)$.

${ }^{6} Y=66,7136+0,599052^{\star \star \star} n-0,00523938^{* \star *} n^{2}\left(R^{2}=0,96\right)$.

\# Médias seguidas por letras iguais na coluna não diferem pelo teste $F(P>0,05)$.

*** Significância das equações de regressão $(P<0,10)$.

\# Means within a column followed by the same letters do not differ $(P>.05)$.

*** Significance of the regression equations $(P<.10)$.

Tabela 8 - Médias, coeficientes de variação $(C V)$ e de determinação $\left(R^{2}\right)$ e equações de regressão ajustadas para as digestibilidades aparentes de matéria seca (MS), matéria orgânica (MO), proteína bruta (PB), extrato etéreo (EE) e carboidratos totais (CHOT), em função do nível (n) de concentrado e dos teores de PB das dietas de bovinos Nelore, na fase de terminação

Table 8 - Means, coefficients of variation $(C V)$ and determination $\left(R^{2}\right)$ and fitted regression equations for the dry matter (DM), organic matter $(O M)$, crude protein $(C P)$, ether extract $(E E)$, and total carbohydrates $(T C H O)$ apparent digestibilities, on the level of concentrate $(n)$ and crude protein $(C P)$ contents of the diets fed to Nellore bulls in the finishing phase

\begin{tabular}{|c|c|c|c|c|c|c|c|}
\hline \multirow[t]{2}{*}{$\begin{array}{l}\text { Variáveis } \\
\text { Variables }\end{array}$} & \multicolumn{4}{|c|}{$\begin{array}{l}\text { Nível de concentrado (\%) } \\
\text { Level of concentrate (\%) }\end{array}$} & \multicolumn{2}{|c|}{$\begin{array}{l}\text { Teores de } \mathrm{PB}(\%) \\
C P \text { contents }(\%)\end{array}$} & \multirow[t]{2}{*}{$\begin{array}{l}\mathrm{CV} \\
(\%)\end{array}$} \\
\hline & 20 & 40 & 60 & 80 & 15 & 18 & \\
\hline $\mathrm{DMS}^{1}$ & 75,66 & 79,93 & 79,94 & 80,80 & $78,29^{a}$ & $79,87^{\mathrm{a}}$ & 2,42 \\
\hline $\mathrm{DMO}^{2}$ & 77,06 & 81,33 & 81,36 & 82,23 & $79,72^{\mathrm{a}}$ & $81,27^{\mathrm{a}}$ & 2,05 \\
\hline $\mathrm{DPB}^{3}$ & 78,64 & 79,72 & 79,71 & 74,61 & $77,55^{\mathrm{a}}$ & $78,78^{\mathrm{a}}$ & 4,68 \\
\hline $\mathrm{DEE}^{4}$ & 74,77 & 84,37 & 89,73 & 85,04 & $82,73^{\mathrm{a}}$ & $84,22^{\mathrm{a}}$ & 11,14 \\
\hline DCHOT $^{5}$ & 76,74 & 81,56 & 81,52 & 83,66 & $80,02^{\mathrm{a}}$ & $81,72^{\mathrm{a}}$ & 2,29 \\
\hline
\end{tabular}

$1 Y=75,2227+0,0772234^{* * *} n\left(r^{2}=0,74\right)$

$2 Y=72,3761+0,289519^{* * *} n-0,00211916^{* * *} n^{2}\left(R^{2}=0,92\right)$.

$3 \mathrm{Y}=78,17 ; \quad 4 \mathrm{Y}=83,47 ; 5 \mathrm{Y}=75,6874+0,103651^{* * *} \mathrm{n}\left(\mathrm{r}^{2}=0,83\right)$

*** Significância das equações de regressão $(P<0,10)$.

*** Significance of the regression equations $(P<.10)$.

\section{R. Bras. Zootec., v.31, n.2, p.1033-1041, 2002 (suplemento)}


interação entre a porcentagem de proteína bruta e o nível de concentrado da dieta. O coeficiente de digestibilidade da FDN das rações com $15 \%$ de PB não foi influenciado pelo nível de concentrado da dieta, enquanto, para as rações com $18 \%$ de PB, houve redução linear com o aumento do nível de concentrado. O mesmo comportamento foi observado para a digestibilidade da FDA.

Os nutrientes digestíveis totais (NDT) das rações com 15\% de PB apresentaram aumento linear, em função do aumento do nível de concentrado da dieta, enquanto, para as rações com $18 \%$ de PB, estimaram-se teores máximos de NDT de $83,84 \%$ com $57,21 \%$ de concentrados. Tais resultados estão de acordo com Ladeira et al. (1999).

\section{Conclusões}

Dietas com 40 a $60 \%$ de concentrado resultaram em maiores consumos de nutrientes na fase de recria e na fase de terminação, dietas com 20 a $40 \%$ de concentrado.

$\mathrm{Na}$ fase de recria, os teores de proteína bruta das dietas não influenciaram os consumos e as digestibilidades dos nutrientes. Na fase terminação, a digestibilidade da porção fibrosa da dieta com $15 \%$ de PB não foi influenciada pelo nível de concentrado, porém para as dietas com $18 \%$ de $\mathrm{PB}$ houve redução linear da digestibilidade da FDN e da FDA, com o aumento do nível de concentrado. Os animais na fase de crescimento apresentaram maior capacidade de consumo de MS e FDN, em porcentagem do PV e em $\mathrm{g} / \mathrm{kg}$ de $\mathrm{PV}^{0,75}$, que os animais durante a fase de terminação.

\section{Literatura Citada}

BERCHIELLI, T.T. Efeito da relação volumoso: concentrado sobre a partição da digestão, a síntese de proteína microbiana, produção de ácidos graxos voláteis e o desempenho de novilhos em confinamento. Belo Horizonte: Universidade Federal de Minas Gerais, 1994. 104p. Tese (Doutorado em Zootecnia) - Universidade Federal de Minas Gerais, 1994.

CARDOSO, R.C.; VALADARES FILHO, S.C.; COELHO DA SILVA, J.F. et al. Síntese microbiana, $\mathrm{pH}$ e concentração de amônia ruminal e balanço de compostos nitrogenados, em novilhos F1 limousin $\mathrm{x}$ nelore. Revista Brasileira de Zootecnia, v.29, n.6, p.1844-1852, 2000.

CATON, J.S.; DHUYVETTER, D.V. Influence of energy supplementation on grazing ruminants: Requirements and responses. Journal of Animal Science, v.75, p.533-542, 1997.

R. Bras. Zootec., v.31, n.2, p.1033-1041, 2002 (suplemento)
DIAS, H.L.C., VALADARES FILHO, S.C., COELHO DA SILVA, J.F. et al. Consumo e digestões totais e parciais em novilhos F1 Limousin $\mathrm{x}$ Nelore alimentados com dietas contendo cinco níveis de concentrado. Revista Brasileira de Zootecnia, v.29, n.2, p.45-554. 2000.

FERREIRA, M.A.; VALADARES FILHO, S.C.; COELHO DA SILVA, J.F. et al. Consumo, conversão alimentar, ganho de peso e características da carcaça de bovinos F1 Simental x Nelore. Revista Brasileira de Zootecnia, v.28, n.2, p.343351, 1999.

GESUALDI Jr., A.; PAULINO, M.F.; VALADARES FILHO, S.C. et al. Níveis de concentrado na dieta de novilhos F1 Limousin x Nelore: consumo, conversão alimentar e ganho de peso. Revista Brasileira de Zootecnia, v.29, n.5, p.14581466, 2000.

HUSSEIN, H.S.; MERCHEN, N.R.; FAHEY Jr., G.C. Effects of forage level and canola seed supplementation on site and extent of digestion of organic matter, carbohydrates, and energy by steers. Journal of Animal Science, v.73, p.24582468, 1995.

ÍTAVO, L.C.V. Consumo, digestibilidade e eficiência microbiana de novilhos alimentados com dietas contendo vários níveis de concentrado, utilizando diferentes indicadores e períodos de coleta. Viçosa, MG: Universidade Federal de Viçosa, 2001. 114p. Tese (Doutorado em Zootecnia) - Universidade Federal de Viçosa, 2001.

KÖSTER, H.H.; COCHRAN, R.C.; TITGEMEYER, E.C. et al. Effect of increasing degradable intake protein on intake and digestion of low-quality, tallgrass-prairie forage by beef cows. Journal of Animal Science, v.74, p.2473-2481, 1996.

LADEIRA, M.M.; VALADARES FILHO, S.C.; COELHO DA SILVA, J.F. et al. Consumo e digestibilidades aparentes totais e parciais de dietas contendo diferentes níveis de concentrado, em novilhos Nelore. Revista Brasileira de Zootecnia, v.28, n.2, p.395-403, 1999.

MERTENS, D.R. Regulation of forage intake. In: NATIONAL CONFERENCE ON FORAGE QUALITY. EVALUATION AND UTILIZATION, 1994. Proceedings... Lincoln: University of Nebraska. 1994. p.450-493.

NATIONAL RESEARCH COUNCIL - NRC. Nutrient requirements of beef cattle. 7.ed. Washington, D.C.: National Academy Press, 1996. 242p.

NATIONAL RESEARCH COUNCIL - NRC. Nutrient requirements of beef cattle. 6.ed. Washington, D.C.: National Academy Press, 1984. 90p.

SILVA, D.J. Análise de alimentos (métodos químicos e biológicos). Viçosa, MG: Universidade Federal Viçosa, 1990. $165 \mathrm{p}$.

SNIFFEN, C.J.; O'CONNOR, J.D.; Van SOEST, P.J. et al. A net carbohydrate and protein system for evaluating cattle diets: II. Carbohydrate and protein availability. Journal of Animal Science, v.70, p.3562-3577, 1992.

UNIVERSIDADE FEDERAL DE VIÇOSA - UFV. SAEG Sistema de análises estatísticas e genética. Viçosa, MG: 1995. (Apostila).

VALADARES, R.F.D.; GONÇALVES, L.C.; RODRÍGUEZ, N.M. et al. Níveis de proteína em dietas de bovinos. 1. Consumo e digestibilidade aparente totais e parciais. Revista Brasileira de Zootecnia, v.26, n.6, p.1252-1258, 1997.

Recebido em: 10/08/01 Aceito em: 01/02/02 